\title{
Prevalence and characteristics of diabetic kidney disease in type 2 diabetic patients in Abidjan, Côte d'Ivoire
}

\author{
Sindou Sanogo ${ }^{1}$, Serge Didier Konan ${ }^{1}$, Kouamé Hubert Yao $^{1^{*}}$, Emma Kouassi $^{2}$, Séry Patrick Diopoh ${ }^{1}$, Jean Aka $^{1}$, \\ Randolphe Niava ${ }^{1}$, Amos Ankotche ${ }^{2}$
}

${ }^{1}$ Department of Nephrology and Internal Medicine, University Hospital of Treichville, Abidjan, Côte d'Ivoire ${ }^{2}$ Division of Diabetology, University-Hospital of Treichville, Abidjan, Côte d'Ivoire

\section{A R T I C L E I N F O}

\section{Article Type:}

Original

\section{Article History:}

Received: 20 April 2018

Accepted: 14 July 2018

ePublished: 20 July 2018

\section{Keywords:}

Type 2 diabetes

Nephropathy

Obesity

Hypertension

Diabetic kidney disease

\begin{abstract}
A B S T R A C T
Introduction: Diabetes mellitus is a disease whose prevalence has been steadily increasing worldwide.

Objectives: To evaluate the prevalence of diabetic kidney disease and to identify the associated factors in type 2 diabetic patients.

Material and Methods: This was a descriptive and analytical cross-sectional study. The study was conducted over a period from January to June 2016, among patients with type 2 diabetes, followed up at the Division of Diabetology of the University Hospital of Treichville, Abidjan. Results: Of 154 included patients, diabetic nephropathy (DN) was observed in 40 cases $(25.9 \%$ prevalence). We observed a female predominance (sex ratio; 0.17 ) and the mean age of $57.7 \pm$ 11 years. Based on the K/DOQI guidelines, half of our patients had stage 3 kidney disease. Complications such as diabetic retinopathy (100\%), hypertension (HT) (75\%), dyslipidemia $(45 \%)$ and obesity $(30 \%)$ were found. Factors such as female sex $(P=0.001$; OR $[95 \% \mathrm{CI}]=$ $4.76[1.85-12.19])$, a range 55-65 years old $(P=0.010$; OR $[95 \% \mathrm{CI}]=2.64[1.26-5.53])$, obesity $(P=0.012$; OR $[95 \% \mathrm{CI}]=3.06[1.27-7.36])$, hypertension $(P=0.0001 ;$ OR $[95 \% \mathrm{CI}]=4.77$ $[2.12-10.71])$ and $\mathrm{HbA1c}<7 \%(P=0.002$; OR $[94 \% \mathrm{CI}]=3.42[1.57-7.44])$ were associated with nephropathy by multivariate analysis.

Conclusion: the prevalence of diabetic kidney disease is high in our study. The associated factors are non-modifiable such as female gender and age, but also modifiable such as obesity and hypertension.
\end{abstract}

Implication for health policy/practice/research/medical education:

Our study showed that one out of four type 2 diabetic patients had nephropathy. Modifiable factors such as obesity and hypertension were associated with it. Their systematic management could help to reduce the diabetic kidney disease.

Please cite this paper as: Sanogo S, Konan SD, Yao KH, Kouassi E, Diopoh SP, Aka J, et al. Prevalence and characteristics of diabetic kidney disease in type 2 diabetic patients in Abidjan, Côte d'Ivoire. J Nephropharmacol. 2018;7(2):98-103.

\section{Introduction}

Diabetes mellitus is a disease whose prevalence has been steadily increasing worldwide. The rise in the populations' life expectancy, and the inexorable progression of overweight and obesity in all the countries of the world have already led this disease to an "epidemic" (1).

Globally, the International Diabetes Federation (IDF) estimates that diabetes affects approximately 300 million individuals, and predicts that diabetes will affect nearly 438 million people in 2030 , (7.8\% of the adult population). This corresponds to a $54 \%$ increase in 20 years. Moreover, at least $70 \%$ of these subjects will be located in the "poverty belt" of the globe, particularly in Sub-Saharan Africa $(2,3)$. In the United States, the number of diabetic patients that was around 23 million for a population of 301 million inhabitants, will be 44 million in 2034 (4). In France, the prevalence of type 2 diabetes was $4 \%$ in 2007 (more than 2.2 million for 63.8 million inhabitants). If the French trend matches that of the United States, the number of patients with type 2 diabetes will be more than 4.4 million in 2034 (5). In Africa, 22 million people live with diabetes (5.1\% prevalence) (3). In Côte d'Ivoire, the in-hospital 
prevalence of diabetes mellitus varied between 3\% and $7.5 \%$ according to the study of Lokrou in 1986 (6). This prevalence was $4.9 \%$ in 2012 and $5.19 \%$ in 2013 according to the International Diabetes Federation (IDF) (7). This is especially type 2 diabetes whose extent is such that we now speak of "pandemic" (5).

This condition is associated with high morbidity and overt mortality, owing to the high prevalence of acute (metabolic comas) and chronic complications, especially the cardiovascular and renal diseases (8). Diabetic nephropathy (DN) (diabetic kidney disease) is one of the most common and severe complications of diabetes. The prevalence of albuminuria $>30 \mathrm{mg} / 24 \mathrm{~h}$ is from $20 \%$ to $30 \%$ among diabetic people. The percentage of diabetic people among dialysis patients is $13 \%$ in France and $30 \%$ in the United States and the Scandinavian countries (9). In the West, DN is the leading cause of dialysis. In sub-Saharan Africa in general, it is the second leading cause after hypertension, but the third leading cause in Côte d'Ivoire after hypertension and HIV infection (10). In our practice, hospital data show that diabetic kidney disease is at the stage of end-stage chronic kidney disease (ESCKD) at the time of diagnosis in one-third of cases. It has been occurring in type 2 diabetic people with chronic hyperglycemia for an average of nine years and is associated with other complications such as hypertension, heart disease and lower extremity arterial disease. In this context, the mortality rate is high before dialysis, around $22 \%(11)$.

In 2012, an outpatient unit (Division of Diabetology) was created within the University Hospital of Treichville to improve patient follow-up and reduce the occurrence of serious complications.

\section{Objectives}

This study aims to assess the prevalence of $\mathrm{DN}$ and to identify the associated risk factors for type 2 diabetic patients followed up in this division.

\section{Patients and Methods}

\section{Study patients}

This study was a descriptive cross-sectional and conducted between January to June 2016, at the Division of Diabetology of the University Hospital of Treichville (Abidjan). This division's main purpose is the outpatient management of diabetic and hypertensive patients. All type 2 diabetic patients regularly followed up, and presenting with microalbuminuria and/or abundant proteinuria and/or glomerular filtration rate (GFR) $<60 \mathrm{~mL} / \mathrm{min}$ associated with diabetic retinopathy were included. Type 2 diabetic patients with incomplete laboratory tests were not included in our study.

\section{Variables}

We performed an Uri-Check 10SG (STANBIO) Multistix urine strip test to eliminate leukocyturia and/or nitrituria.
The microalbuminuria test was performed on a freshly voided urine specimen using a HEMOCUE Albumin 201 system when the urine dipstick test was negative.

For each included patient, the following data were collected using a standardized survey form; sociodemographic data (age, gender and occupation), clinical data (diabetes duration, existence of retinopathy or not, weight, height, blood pressure, edema and albuminuria), and biological data (serum creatinine, fasting blood glucose, glycated hemoglobin, total cholesterol, triglycerides, and High-density lipoprotein cholesterol [HDL-C]).

\section{Definitions}

The micro-albuminuria test was said to be positive for values between $20 \mathrm{mg} / \mathrm{min}$ to $200 \mathrm{mg} / \mathrm{min}$ on urines voided less than 30 minutes (12). DN (diabetic kidney disease) was defined by the presence of micro-albuminuria and/or decreased GFR, associated with the presence of diabetic retinopathy (13). The GFR was evaluated with serum creatinine using the MDRD equation. Renal disease was defined and classified according to the K/DOQI (Kidney Disease Outcomes Quality Initiative) guidelines (14).

Patients underwent a glycated hemoglobin (HbA1c) test using a QUO-Lab system. Diabetes was well controlled for a glycated hemoglobin (HbAlc) level $<7 \%$, moderately controlled for an HbA1c level between $7 \%$ and $9 \%$ and poorly controlled for an HbA1c level $\geq 10 \%$ (15). Diabetes was defined as fasting blood glucose greater than $1.26 \mathrm{~g} / \mathrm{L}$ or normal blood glucose in a participant on antidiabetic therapy (16). Obesity was confirmed for a body mass index [weight $(\mathrm{kg}) /$ height $(\mathrm{m})^{2}$ ] greater than $30 \mathrm{~kg} / \mathrm{m}^{2}$.

The blood pressure was measured according to the World Health Organization (WHO) (17) using an electronic sphygmomanometer on the right arms of participants in a sitting position, after at least 5 minutes of rest. Hypertension is defined as systolic blood pressure value $\geq 140 \mathrm{~mm} \mathrm{Hg}$ and/or diastolic blood pressure value $\geq 90 \mathrm{~mm} \mathrm{Hg}$ or normal blood pressure in people on antihypertensive therapy (18). Serum creatinine was measured by the Jaffé kinetic method.

\section{Ethical considerations}

The study protocol was in accordance with the Declaration of Helsinki. Participants gave their verbal consent to participate in this study. This investigation was conducted as part of an outpatient follow-up.

\section{Statistical analysis}

Data were recorded into an Excel database and then analyzed using the SPSS software version 22. The quantitative variables were explained with the means \pm standard deviation when their distribution was normal, or otherwise, with the medians and percentiles. In univariate analysis, the proportions of qualitative variables were compared between subjects with kidney disease and 
subjects without kidney disease using a chi-square test or a Fisher's exact test. As regards the quantitative parameters, the means and medians were compared by an ANOVA test. The relative quantitative variables were transformed into categorical variables according to pathological norms. The qualitative or categorical parameters with $P<0.20$ were included in a logistic regression model. The association between the variable and the various parameters was calculated by the odds ratio (OR). The threshold of $P<0.05$ was thought significant.

\section{Results}

Our study population consisted of 96 female subjects and 58 male subjects. The mean age was $56.3 \pm 11$ years, and all age groups above 35 years were included. Diabetes had been progressing for $4.5 \pm 3.6$ years on average. The disease progression duration was $<3$ years in $62.3 \%$ of cases, between 3 and 5 years in $9.1 \%$ and $\geq 5$ years in $28.6 \%$. Complications such as obesity (54.5\%), hypertension (48.1\%), dyslipidemia (42.9\%) and retinopathy $(32.5 \%)$ were found. HbA1c level was $9.04 \pm 2.46 \%$ on average, and it was below $7 \%$ in $26 \%$ of cases ( $7 \%-9 \%$ in $29.3 \%$ and $\geq 9 \%$ in $44.2 \%$ ) (Table 1). Microalbuminuria was observed in 80 cases (51.6\%). According to the K/DOQI classification, $15 \%$ of cases had stage 2 kidney disease, $50 \%$ had stage 3 kidney disease, $30 \%$ had stage 4 kidney disease and 5\% had stage 5 kidney disease. Of 154 type 2 diabetic patients, DN was observed in 40 cases (25.9\% prevalence).

In univariate analysis, we compared the group of patients with DN to the group without nephropathy. It was found that the proportion of female subjects was statistically higher in DN group. Similarly, the proportion of subjects of 55 to 65 years of age, with obesity, hypertension, retinopathy, and $\mathrm{HbA} 1 \mathrm{c}<7 \%$ was greater in the group with DN (Table 1).

In multivariate analysis, age, obesity, hypertension, and HbA1c $<7 \%$ appeared to be associated with the presence of DN in our study (Table 2).

When comparing patients with $\mathrm{HbAlc}<7 \%$ to those with $\mathrm{HbAlc} \geq 7 \%$, we observed a greater proportion of subjects between 55 to 65 years of age, subjects having microalbuminuria, nephropathy, hypertension, and retinopathy in the group with $\mathrm{HbAlc}<7 \%$ (Table 3 ).

\section{Discussion}

Microangiopathic complications are common in type 2 diabetes mellitus. Their overall prevalence can reach $30 \%$ among newly diagnosed type 2 diabetic people (19). At this stage of new discovery, the prevalence of kidney disease is around $10.5 \%$ (19). In the absence of treatment and care, this proportion will rise with the progression of diabetes mellitus. This explains the high prevalence reported in our study population that had a mean diabetes duration of four years.

The female gender appeared to be associated with kidney disease in our patients. Our study population contained mostly of female subjects. Overall, in 2010, the global prevalence of stages 1 to 5 chronic kidney disease

Table 1. Characteristics of type 2 diabetic patients

\begin{tabular}{|c|c|c|c|c|c|}
\hline & Total $(n=154)$ & With nephropathy $(n=40)$ & Without nephropathy $(n=114)$ & $P$ value & OR $(95 \% \mathrm{Cl})$ \\
\hline Male & $37.7 \%(58 / 154)$ & $15 \%(6 / 40)$ & $45.6 \%(52 / 114)$ & 0.0001 & $0.29(0.13-0.65)$ \\
\hline Female & $62.3 \%(96 / 154)$ & $85 \%(34 / 40)$ & $54.4 \%(62 / 114)$ & 0.0001 & $3.44(1.53-7.69)$ \\
\hline \multicolumn{6}{|l|}{ Age (y) } \\
\hline Means & $56.3 \pm 11$ & $57.7 \pm 11$ & $55.8 \pm 11$ & 0.38 & \\
\hline$[35-45[$ & $19.5 \%(30 / 154)$ & $15 \%(6 / 40)$ & $21.1 \%(24 / 114)$ & 0.28 & $0.72(0.33-1.57)$ \\
\hline$[45-55[$ & $23.4 \%(36 / 154)$ & $15 \%(6 / 40)$ & $26.3 \%(30 / 114)$ & 0.10 & $0.57(0.26-1.26)$ \\
\hline [55-65[ & $35.1 \%(54 / 154)$ & $50 \%(20 / 40)$ & $29.8 \%(34 / 114)$ & 0.018 & $1.85(1.09-3.12)$ \\
\hline$\geq 65$ & $22.1 \%(34 / 154)$ & $20 \%(8 / 40)$ & $22.8 \%(26 / 114)$ & 0.45 & $0.88(0.44-1.73)$ \\
\hline \multicolumn{6}{|l|}{ Duration (y) } \\
\hline Means & $4.49 \pm 5.6$ & $4.3 \pm 4.15$ & $4.5 \pm 6.06$ & 0.80 & \\
\hline$<3$ & $62.3 \%(96 / 154)$ & $60 \%(24 / 40)$ & $63.2 \%(72 / 114)$ & 0.43 & $0.90(0.52-1.55)$ \\
\hline$[3-5[$ & $9.1 \%(14 / 154)$ & $15 \%(6 / 40)$ & $7 \%(8 / 114)$ & 0.11 & $1.76(0.90-3.45)$ \\
\hline$\geq 5$ & $28.6 \%(44 / 154)$ & $25 \%(10 / 40)$ & $29.8 \%(34 / 114)$ & 0.35 & $0.83(0.44-1.55)$ \\
\hline \multicolumn{6}{|c|}{ Associated complications } \\
\hline Obesity & $54.5 \%(84 / 154)$ & $30 \%(12 / 40)$ & $12.3 \%(14 / 114)$ & 0.01 & $2.11(1.24-3.58)$ \\
\hline Hypertension & $48.1 \%(74 / 154)$ & $75 \%(30 / 40)$ & $38.6 \%(44 / 114)$ & 0.0001 & $3.24(1.70-6.16)$ \\
\hline Dyslipidemia & $42.9 \%(66 / 154)$ & $45 \%(18 / 40)$ & $19.3 \%(22 / 114)$ & 0.44 & $1.09(0.63-1.86)$ \\
\hline Retinopathy & $32.5 \%(50 / 154)$ & $100 \%(40 / 40)$ & $8.8 \%(10 / 114)$ & 0.0001 & 5 (2.87-8.69) \\
\hline \multicolumn{6}{|l|}{$\mathrm{HbA1C}(\%)$} \\
\hline Means & $9.04 \pm 2.46$ & $8.47 \pm 2.54$ & $9.24 \pm 2.54$ & 0.09 & \\
\hline$<7$ & $26 \%(40 / 154)$ & $45 \%(18 / 40)$ & $19.3 \%(22 / 114)$ & 0.002 & $2.33(1.40-3.87)$ \\
\hline [7-9[ & $29.3 \%(46 / 154)$ & $20 \%(8 / 40)$ & $33.3 \%(38 / 114)$ & 0.08 & $0.58(0.29-1.17)$ \\
\hline$\geq 9$ & $44.2 \%(68 / 154)$ & $35 \%(14 / 40)$ & $47.4 \%(54 / 114)$ & 0.12 & $0.68(0.38-1.20)$ \\
\hline
\end{tabular}

HbA1C, glycated hemoglobin. 
Table 2. Risk factors of diabetic nephropathy in multivariate analysis

\begin{tabular}{lllcc}
\hline \multirow{2}{*}{ Variables } & \multirow{2}{*}{$\boldsymbol{P}$ value } & \multirow{2}{*}{ OR } & \multicolumn{2}{c}{ 95\% Cl } \\
\cline { 4 - 5 } & & & Lower & Higher \\
\hline Female & 0.001 & 4.76 & 1.85 & 12.19 \\
Age [55-65[ & 0.010 & 2.64 & 1.26 & 5.53 \\
Retinopathy & 0.995 & - & - & - \\
Obesity & 0.012 & 3.06 & 1.27 & 7.36 \\
Hypertension & 0.0001 & 4.77 & 2.12 & 10.71 \\
Dyslipidemia & 0.750 & - & - & - \\
HbA1C <7\% & 0.002 & 3.42 & 1.57 & 7.44 \\
\hline
\end{tabular}

HbA1C, glycated hemoglobin.

(CKD) among adults aged 20 years and older was $10.4 \%$ for men and $11.8 \%$ for women. This group is comprised of $8.6 \%$ men and $9.6 \%$ women in high-income countries, and $10.6 \%$ men and $12.5 \%$ women in low- and middle-income countries (20). Furthermore, Earle et al observed an early decline in renal function in type 2 diabetic women (21). According to these authors, early renal functional decline in women is reportedly related to vascular stiffness increase that may be associated with visceral fat accumulation determined by waist circumference. Obesity was identified as a predictor of kidney disease (22), as reported in our study. This association between obesity and renal disease is stronger in diabetic people with chronic kidney disease, but also significantly high in non-diabetic people with end-stage $\operatorname{CKD}(23,24)$. Obesity leads to complex metabolic abnormalities that have extensive impacts on kidneys. The precise mechanisms through which obesity may cause chronic kidney disease or make it progress remain unclear. Obese people are exposed to co-morbid factors like diabetes or hypertension. However, there are also the effects of adiposity that could directly affect the kidneys. Kidneys are affected by endocrine activity of the adipose tissue with the creation of adiponectin and leptin. These include the development of inflammation, the abnormal lipid metabolism, the activation of the reninangiotensin-aldosterone system, increased production of insulin and insulin resistance (25). These several effects lead to particular kidney pathologic changes.

In more than half of cases, microalbuminuria was present in our patients. However, the diagnosis of diabetic kidney disease was confirmed in only half of the microalbuminuric cases, based on our diagnostic criteria. In the study by Ranjit et al, patients with diabetic kidney disease had a higher prevalence of microalbuminuria and retinopathy, as compared to those with non-DN (26). However, the prevalence of retinopathy, although high among our patients, was not associated with the existence of diabetic kidney disease.

The natural history of diabetes teaches us that microalbuminuria gradually progresses to end-stage CKD, through overt nephropathy during which hypertension is almost steady and severe. This explains why hypertension is associated with diabetic kidney disease in our study. Thus, hypertension and its duration appear as a risk factor for diabetic kidney disease (27-29). As for home pulse pressure, its increased level appears to be an independent predictor of diabetic kidney disease progression (30).

In univariate analysis, patients with $\mathrm{DN}$ had a greater proportion of $\mathrm{HbAlc}<7 \%$, thus better glycemic control.

Table 3. Characteristics of patients according to glycated hemoglobin value

\begin{tabular}{|c|c|c|c|c|}
\hline & $\mathrm{HbA} 1 \mathrm{C}<7 \%$ & $\mathrm{HbA} 1 \mathrm{C} \geq 7 \%$ & $P$ value & OR $(95 \% \mathrm{Cl})$ \\
\hline Male & $40 \%(16 / 40)$ & $36.8 \%(42 / 114)$ & 0.43 & $1.10(0.64-1.89)$ \\
\hline Female & $60 \%(24 / 40)$ & $63.2 \%(72 / 114)$ & & \\
\hline \multicolumn{5}{|l|}{ Age (y) } \\
\hline Means & $59.6 \pm 10.6$ & $55.15 \pm 11.7$ & 0.035 & \\
\hline [35-45[ & $10 \%(4 / 40)$ & $22.8 \%(26 / 114)$ & 0.05 & $0.45(0.17-1.19)$ \\
\hline$[45-55[$ & $5 \%(2 / 40)$ & $29.8 \%(34 / 114)$ & 0.001 & 1.39 (1.20-1.60) \\
\hline$[55-65[$ & $60 \%(24 / 40)$ & $26.3 \%(30 / 114)$ & 0.0001 & $2.48(1.44-4.27)$ \\
\hline$\geq 65$ & $25 \%(10 / 40)$ & $21.1 \%(24 / 114)$ & 0.37 & $1.17(0.64-2.15)$ \\
\hline \multicolumn{5}{|l|}{ Duration (y) } \\
\hline$<3$ & $55 \%(22 / 40)$ & $64.9 \%(74 / 114)$ & 0.17 & $0.73(0.43-1.25)$ \\
\hline [3-5[ & $15 \%(6 / 40)$ & $7 \%(8 / 114)$ & 0.11 & $1.76(0.90-3.45)$ \\
\hline$\geq 5$ & $30 \%(12 / 40)$ & $28.1 \%(32 / 114)$ & 0.48 & $1.07(0.60-1.91)$ \\
\hline \multicolumn{5}{|l|}{ Complications } \\
\hline Microalbuminuria & $70 \%(28 / 40)$ & $45.6 \%(52 / 114)$ & 0.006 & $1.28(1.06-1.55)$ \\
\hline Nephropathy & $45 \%(18 / 40)$ & $19.3 \%(22 / 114)$ & 0.002 & $2.33(1.40-3.87)$ \\
\hline Retinopathy & $45 \%(18 / 40)$ & $28.1 \%(32 / 114)$ & 0.04 & $1.70(1.00-2.87)$ \\
\hline Hypertension & $65 \%(26 / 40)$ & $42.1 \%(48 / 114)$ & 0.01 & $2(1.13-3.54)$ \\
\hline Obesity & $20 \%(8 / 40)$ & $15.8 \%(18 / 114)$ & 0.34 & $1.23(0.64-2.35)$ \\
\hline Dyslipidemia & $52.5 \%(21 / 40)$ & $39.5 \%(45 / 114)$ & 0.10 & $1.47(0.86-2.50)$ \\
\hline
\end{tabular}

HbA1C, glycated hemoglobin. 
Besides this, $60 \%$ of these patients had a GFR lower than $60 \mathrm{~mL} / \mathrm{min}$. The needs for insulin will reduce with the severity of renal failure. Indeed, one of the metabolic functions of the kidney is to ensure the catabolism of small-molecular-weight proteins (including insulin), and gluconeogenesis from lactate in particular (31). During kidney disease, these functions are impaired, thus leading to a trend toward normalization of blood glucose.

\section{Conclusion}

The prevalence of $\mathrm{DN}$ is high in a center that is less than five years old. The associated factors are non-modifiable such as female gender, age, but also modifiable such as obesity and hypertension. Optimal management of these factors may help curb the progression of this disease.

\section{Limitations of the study}

This is a single center study. Larger studies on this aspect of diabetic patients in our region is necessary.

\section{Acknowledgements}

We thank our staffs and the division of diabetology for their participation in the study.

\section{Authors' contribution}

KHY made a substantial contribution to the conception, design, analysis and interpretation of data. $\mathrm{He}$ was also involved in drafting the manuscript and revising it critically for important intellectual content. SS, EM, SDK and JA collected data. SPD and AA revised the manuscript critically for important intellectual content. All authors read and approved the final paper.

\section{Conflicts of interest}

The authors declare no conflict of interest.

\section{Ethical considerations}

Ethical issues (including plagiarism, data fabrication, double publication) have been completely observed by the authors.

\section{Funding/Support}

No funding was received for this study.

\section{References}

1. HU FB. Globalisation of diabetes: The role of diet, lifestyle and genes. Diabetes care. 2011; 34:1249-57. doi: 10.2337/ dc11-0442.

2. Cordonnier DJ, Zmirou D, Benhamou PY, Halimi S, Ledoux F, Guiserix J. Epidemiology, development and treatment of end-stage renal failure in type 2 (non-insulin-dependent) diabetes mellitus. The case of mainland France and of overseas French territories. Diabetologia. 1993;36:1109-12.

3. Ogurtsova K, da Rocha Fernandes JD, Huang Y, Linnenkamp U, Guariguata L, Cho NH, et al. IDF Diabetes Atlas: Global estimates for the prevalence of diabetes for
2015 and 2040. Diabetes Res Clin Pract. 2017;128:40-50. doi: $\quad$ 10.1016/j.diabres.2017.03.024.

4. Huang ES, Basu A, O'Grady M, Capretta JC. Projecting the future diabetes population size and related costs for US. Diabetes care. 2009;32:2225-9. doi: 10.2337/dc09-0459.

5. Detournay B, Raccah D, Cadilhac M, Eschwege E. Epidemiology and costs of diabetes treated with insulin in France. Diabetes Metab. 2005;31:3-18.

6. Lokrou A. Epidemiology and clinical aspects of diabetes mellitus in hospitals in Côte d'Ivoire. Rev Endocrinol Clin.1986;6:579-88.

7. IDF. Diabetes Atlas. 3rd ed. 2011;6:2-56.

8. Marre M, Chatellier G, Leblanc H, Guyene TT, Menard J, Passa P. Prevention of diabetic nephropathy with enalapril in normotensive diabetics with microalbuminuria. BMJ.1998;297:1092-5.

9. Molitch ME, Steffes M, Sun W, Rutledge B, Cleary P, de Boer IH, et al. Development and progression of renal insufficiency with and without albuminuria in adults with type 1 diabetes in the diabetes control and complications trial and the epidemiology of diabetes interventions and complications study. Diabetes Care. 2010;33:1536-43. doi: 10.2337/dc09-1098.

10. Yao HK, Konan SD, Sanogo S, Diopoh SP, Diallo AD. Prevalence and Risk Factors of Chronic Kidney Disease in Cote D'Ivoire: An Analytic Study Conducted in the Department of Internal Medicine. Saudi J Kidney Dis Transpl. 2018;29:153-9. doi: 10.4103/1319-2442.225201.

11. Yao KH A. Ankotche Hue lou A, Kouassi YI, Sibally P, Diallo AD. Diabetic nephropathy in Côte d'Ivoire: when the delay in diagnosis makes gravity. ABM. 2011;16:113-7.

12. Gross JL, de Azevedo MJ, Silveiro SP, Canani LH, Caramori ML, Zelmanovitz T. Diabetic nephropathy : Diagnosis, prevention, and treatment. Diabetes Care. 2005;28:164-76. doi:10.2337/diacare.28.1.164.

13. Mogensen CE, Schmitz A, Christensen CK. Comparative renal pathophysiology relevant to IDDM and NIDDM patients. Diabetes Metab Rev. 1988;4:453-83. doi: 10.1002/ dmr.5610040504.

14. National Kidney Foundation. K/DOQI clinical practice guidelines for chronic kidney disease: evaluation, classification and stratification. Am J Kidney Dis. 2002;39:S1-266.

15. American Diabetes Association. Glycemic targets. Diabetes care. 2016;39:S39-46. doi: 10.2337/dc16-S008.

16. Gambara V, Mecca G, Remuzzi G, Bertani T. Heterogeneous nature of renal lesions in type 2 diabetes. J Am Soc Nephrol. 1993;3:1458-66.

17. Chalmers J, MacMahon S, Mancia G, Whitworth J, Beilin L, Hansson L, et al. 1999 World Health OrganizationInternational Society of Hypertension Guidelines for the management of hypertension. Guidelines sub-committee of the World Health Organization. Clin Exp Hypertens. 1999;21:1009-60. doi:10.3109/10641969909061028.

18. Abel N, Contino K, Jain N, Grewal N, Grand E, Hagans I, et al. Eighth Joint National Committee (JNC-8) Guidelines and the Outpatient Management of Hypertension in the African-American Population. N Am J Med Sci. 2015;7:43845. doi: 10.4103/1947-2714.168669.

19. Raman R, Gupta A, Krishna S, Kulothungan V, Sharma T. Prevalence and risk factors for diabetic microvascular 
complications in newly diagnosed type II diabetes mellitus. Sankara Nethralaya Diabetic Retinopathy Epidemiology and Molecular Genetic Study (SN-DREAMS, report 27). J Diabetes Complications. 2012;26:123-8. doi: 10.1016/j. jdiacomp.2012.02.001.

20. Mills KT, Xu Y, Zhang W, Bundy JD, Chen CS, Kelly TN, et al. A systematic analysis of world-wide population-based data on the global burden of chronic kidney disease in 2010. Kidney Int. 2015;88:950-7. doi: 10.1038/ki.2015.230.

21. Earle KA, Ng L, White S, Zitouni K. Sex differences in vascular stiffness and relationship to the risk of renal functional decline in patients with type 2 diabetes. Diab Vasc Dis Res. 2017;14:304-9. doi: 10.1177/1479164116687237.

22. Kaze FF, Halle MP, Mopa HT, Ashuntantang G, Fouda H, Ngogang J, et al. Prevalence and risk factors of chronic kidney disease in urban adult Cameroonians according to three common estimators of the glomerular filtration rate: a cross-sectional study. BMC Nephrol. 2015;16:96. doi: 10.1186/s12882-0150102-9.

23. Lu JL, Molnar MZ, Naseer A, Mikkelsen MK, KalantarZadeh K, Kovesdy CP. Association of age and BMI with kidney function and mortality: a cohort study. Lancet Diabetes Endocrinol. 2015;3:704-14. doi: 10.1016/S22138587(15)00128 -X.

24. Vivante A, Golan E, Tzur D, Leiba A, Tirosh A, Skorecki K, et al. Body mass index in 1.2 million adolescents and risk for end-stage renal disease. Arch Intern Med. 2012;172:164450. doi: 10.1001/2013.jamainternmed.85.

25. Kovesdy CP, Furth S, Zoccali C; World Kidney Day Steering Committee. Obesity and kidney disease: hidden consequences of the epidemic. Saudi J Kidney Dis Transpl. 2017;28:241-52. doi: 10.4103/1319-2442.202776.

26. Unnikrishnan RI, Rema M, Pradeepa R, Deepa M, Shanthirani CS, Deepa R, et al. Prevalence and risk factors of diabetic nephropathy in an urban south Indian population. The Chennai Urban Rural Epidemiology Study (CURES 45). Diabetes Care. 2007;30:2019-24. doi: 10.2337/ dc06-2554.

27. Islam SM, Alam DS, Wahiduzzaman M, Niessen LW, Froeschl G, Ferrari U, et al. Clinical characteristics and complications of patients with type 2 diabetes attending an urban hospital in Bangladesh. Diabetes Metab Syndr. 2015;9:7-13. doi: 10.1016/j.dsx.2014.09.014.

28. Olamoyegun M, Ibraheem W, Iwuala S, Audu M, Kolawole B. Burden and pattern of micro vascular complications in type 2 diabetes in a tertiary health institution in Nigeria. Afr Health Sci. 2015;15:1136-41. doi:10.4314/ahs.v15i4.12.

29. Abougalambou SS, Abougalambou AS. Prevalence and risk factors of microalbuminuria in type 2 diabetes mellitus outpatients at University Sains Malaysia Hospital. Diabetes Metab Syndr. 2013;7:64-7. doi: 10.1016/j.dsx.2013.02.034.

30. Kitagawa N, Ushigome E, Matsumoto S, Oyabu C, Ushigome H, Yokota I, et al. Prognostic significance of home pulse pressure for progression of diabetic nephropathy: KAMOGAWA-HBP study. Hypertens Res. 2018;41:363371. doi: 10.1038/s41440-018-0024-6.

31. Dequiedt P. The functions of the kidney. In: Hydroelectrolytic Equilibrium, Physiology, Physiopathology and Clinical Practice. Science Medicine; 2011. p. 10-11.

Copyright $\odot 2018$ The Author(s); Published by Society of Diabetic Nephropathy Prevention. This is an open-access article distributed under the terms of the Creative Commons Attribution License (http://creativecommons.org/licenses/by/4.0), which permits unrestricted use, distribution, and reproduction in any medium, provided the original work is properly cited. 